\title{
Imaginação e possibilidades metodológicas no ensino de filosofia no contexto da bncc
}

\author{
Imagination and methodological possibilities in the teaching of \\ philosophy in the context of bncc
}

\author{
João Batista Andrade Filho \\ Professor doutor da Secretaria da Educação Básica do Estado do Ceará, Fortaleza, \\ $\mathrm{CE}$, Brasil. \\ jbandradef@gmail.com - https://orcid.org/0000-0002-1196-6711
}

\author{
Evanildo Costeski \\ Professor doutor da Universidade Federal do Ceará, Fortaleza, CE, Brasil. \\ evanildoc@uol.com.br - https://orcid.org/0000-0001-8713-915X
}

Recebido em 12 de junho de 2021

Aprovado em 17 de outubro de 2021

Publicado em 30 de dezembro de 2021

RESUMO: O texto aqui apresentado, em forma de artigo, buscou dar evidência a algumas ideias presentes em um texto mais amplo, oriundo de uma dissertação de mestrado apresentada junto ao Programa de Pós-graduação em Filosofia da Universidade Federal do Ceará, cujo objetivo maior nos fez caminhar na busca de elaboração de metodologias para as aulas de filosofia no Ensino Médio.Tal iniciativa, se deu com a submissão de uma proposta dentro do programa de Mestrado Profissional em Filosofia (PROF-FILO), cuja inspiração teve as obras do escritor irlandês Clive Staples Lewis (18981963), a partir das quais foi possível pensar nas alternativas metodológicas para o ensino de Filosofia no contexto das mudanças do ensino médio, que modificou o status da disciplina, suscitando em quem lida direta ou indiretamente com a disciplina, preocupações e questionamentos sobre sua permanência na grade curricular. Ao longo do percurso de aprofundamento da pesquisa, no tocante à nossa categoria de análise, a mesma se revelou bem mais do que supúnhamos, apresentando-se como importante faculdade que, aliada à razão, permite a lucidez do pensamento, o que nos permitiu compreendê-la como ferramenta metodológica para as aulas de filosofia, o que serviu de incentivo, dentre outras ações, para montarmos um curso de formação filosófica de forma a atender as novas exigências escolares de acordo com as referidas mudanças, notadamente no que diz respeito às diretrizes da Base Nacional Comum Curricular. Assim, vislumbramos a direção em que a filosofia pode aparecer como disciplina eletiva e, num esforço interpretativo, baseado em textos, notadamente documentos oficiais, procuramos suscitar reflexões e indicar caminhos para possíveis readequações concernentes ao seu ensino na educação básica.

Palavras-chave: Imaginação; Ensino de Filosofia; Ensino Médio; BNCC; C. S. Lewis. 
ABSTRACT: The text presented here, in the form of an article, sought to give evidence to some ideas present in a broader text, coming from a master's thesis presented at the Graduate Program in Philosophy of the Federal University of Ceará, whose main objective made us walk in the search for the development of methodologies for philosophy classes in high school. This initiative, took place with the submission of a proposal within the Professional Masters in Philosophy program (PROF-FILO), inspired by the works of Irish writer Clive Staples Lewis (1898-1963), from which it was possible to think about alternatives methodologies for teaching Philosophy in the context of changes in secondary education, which changed the status of the discipline, raising concerns and questions about its permanence in the curriculum in those who deal directly or indirectly with the discipline. Along the path of deepening the research, regarding our category of analysis, it revealed much more than we supposed, presenting itself as an important faculty that, allied to reason, allows the lucidity of thought, which allowed us to understanding it as a methodological tool for philosophy classes, which served as an incentive, among other actions, to set up a philosophical training course in order to meet the new school requirements in accordance with these changes, notably with regard to guidelines of the Common National Curriculum Base. Thus, we glimpse the direction in which philosophy can appear as an elective discipline and, in an interpretive effort, based on texts, notably official documents, we seek to raise reflections and indicate paths for possible readjustments concerning its teaching in basic education.

Keywords: Imagination; Teaching of Philosophy; High school; BNCC; C.S. Lewis.

\section{Introdução}

O presente texto surge a partir de uma proposta, cujo objetivo principal era a elaboração de metodologias para as aulas de filosofia no Ensino Médio, submetida como projeto de mestrado junto do Programa de Mestrado em Filosofia Profissional, e da Universidade Federal do Ceará. A inspiração para esta execução, foram as obras do escritor irlandês Clive Staples Lewis, por terem mostrado o fio da meada que deu início a esta pesquisa, cuja referência aqui elegeu a imaginação como categoria de análise e, ao mesmo tempo, alternativa metodológica para o ensino da referida disciplina. Em nossa caminhada de aprofundamento, ela se revelou bem mais do que supúnhamos, dado que, pelo percurso filosófico que fizemos, nos deparamos com importante faculdade que, aliada à razão, permite a lucidez do pensamento.

Sem essas informações preciosas declaradas acima, é bem comum alguém questionar sobre o que a imaginação tem a ver com a filosofia. A própria condução educacional, de uma maneira geral, tende a encobrir essa relação, e leva as pessoas a questões dessa natureza, porque o alicerce educacional está fundado em uma sólida convicção que privilegiou um certo aspecto de racionalidade impugnante 
daquilo que lhe aparenta ser contrário. Assim é quando nos referimos à imaginação, pois afinal, a palavra costumeiramente está associada a fantasias e, às vezes, até a delírios.

Foi, portanto, pertinente iniciarmos por uma definição diferenciada daquela do senso comum e compartilharmos verdadeiramente o que seja a imaginação, afastando-a dessa visão corriqueira que a põe em oposição à racionalidade e à realidade, e que, portanto, a mostra por um viés corrompido, sem relação com a filosofia.

$\mathrm{Na}$ visão de muitos autores, dentre eles C. S. Lewis, a imaginação é uma faculdade do pensamento humano, que nos torna capazes de pensar, sentir, raciocinar, tomar decisões, criar, estabelecer hábitos e rotinas, decidir o que é ruim e o que é bom. Assim, ela funciona como um arquivo onde estão guardadas as nossas experiências diretas, resultantes de tudo o que vimos, ouvimos, sentimos e vivemos, bem como daquilo que chamam de experiência indireta, fruto de vivências de outras pessoas que, por exemplo, souberam sintetizá-las em uma obra literária. A isto, Lewis (2020) chamou a atenção e propagou a necessidade da experiência indireta que a literatura é capaz de proporcionar, abrindo possibilidades para o pensamento.

É nesse ponto que a imaginação se encontra com a filosofia, pois o ato de filosofar exige a reflexão sobre as experiências humanas naquele sentido socrático do exame de si. A saúde do pensamento solicita que a imaginação analise o máximo possível de experiências, oferecendo parâmetros para que enxerguemos adequadamente a realidade, pois se algo é oferecido sem parâmetro, tende a ser absorvido como verdade inconteste. Como afirmou Araújo (s/d, p. 7), "se, ao invés de enxergarmos a realidade, sempre enxergamos e tão somente aquilo que imaginamos, estamos com a imaginação corrompida."

Dessa forma, em C. S. Lewis, a imaginação é uma aliada do pensamento e que tem influência direta sobre ele e, consequentemente, sobre nossas ações, e a forma como enxergarmos e interpretamos o mundo. A obra de Lewis, na verdade, se revelou como uma proposta educacional de reabilitação da imaginação. De uma maneira geral, Lewis defendeu a recomposição de uma educação integral, no sentido de aliar a razão com outras prerrogativas da mesma forma humanas. 
Perguntar pelo propósito da educação, é uma questão sobre a qual nossas vidas, e a vida da sociedade, descansam (MCGRATH, 2014). Daí porque Lewis rejeitou a tese de que a educação sirva apenas a propósitos instrumentais. Para ele, educar não é simplesmente ensinar aos estudantes certas habilidades

O que planejamos, a partir da obra de Lewis, foi o aprofundamento dessa proposta no conjunto de suas obras, tanto as ficcionais quanto as não-ficcionais, vislumbrando possibilidades metodológicas a serem desvendadas, bem como reflexões filosóficas a serem feitas no conjunto de muitos estudos literários e de crítica literária a serem ainda descortinados, e, muitos estudos históricos a serem apreciados.

Dessa forma, conforme a visão do autor supracitado, a imaginação é um recurso educacional que põe em movimento a própria educação. Isso serviu de parâmetro para que delineássemos nosso propósito de composição da imaginação como recurso pedagógico, notadamente para o ensino de filosofia, elegendo textos lewisianos como tais recursos, tornando possível elaborar a metodologia que nos propusemos, ou seja, aulas de filosofia com textos não-filosóficos, quer dizer ficcionais, caminhando no direcionamento filosófico. E este foi o nosso esforço por aproximar a imaginação à razão.

Tal esforço se dá nesse momento de mudanças no ensino médio e, em particular, no deslocamento da disciplina de Filosofia, conforme o previsto na Base Nacional Comum Curricular (BNCC), contexto propício para discussões e proposições de caminhos para o ensino de filosofia. Aqui, a partir de nosso itinerário, apresentamos uma proposta eletiva para a referida disciplina conforme um modelo de curso apresentado. No entanto, vislumbra-se um vasto horizonte de amplas discussões, debates e possibilidades metodológicas.

\section{O ensino de filosofia e a formação filosófica em disciplinas eletivas}

Após muitas idas e vindas e inquietações acerca da Filosofia enquanto disciplina no Ensino Médio, como costumeiramente mostra e comprova a própria história curricular brasileira no que diz respeito a esta disciplina, e sobre a sua 
instabilidade nas descontinuidades deste currículo escolar brasileiro, novamente os anos de 2016 e 2017 registraram uma movimentação mudancista que resultou em nova reforma do ensino, em que a disciplina de filosofia é destituída de seu posto de obrigatoriedade, passando a ser considerada, de maneira vaga, como estudos e práticas dentro das áreas de conhecimento.

Sequer completara dez anos desde seu retorno compulsório, em 2008, e agora, após muitos esforços, como debates públicos, investimentos, formações, desenvolvimentos de metodologias a partir das ampliações da pós-graduação, tanto lato quanto stricto sensu, e uma Medida Provisória, MP 746/16, fez parecer ter sido tudo em vão. Essa mudança colocou a filosofia em uma situação, aparentemente, pouco favorável.

A obrigatoriedade da disciplina de Filosofia, antes da referida reforma, fora outorgada pela Lei n. ${ }^{\circ} 11.684$ de 2 de junho de 2008, cujo intuito era a alteração da Lei de Diretrizes e Bases da Educação Nacional (LDB), Lei 9.394 de 20 de dezembro de 1996, particularmente em seu Art. 36, inciso IV, incluindo-a obrigatoriamente em todas as séries do Ensino Médio. Conforme afirmou Lindberg (2019), "o retorno do caráter obrigatório da Filosofia no ensino médio, em 2008, reforçou o conjunto de leis existentes em vários estados, impulsionando seu ensino na educação básica em nosso país." Ainda de acordo com o mesmo autor, o impulsionamento a qual a referida lei foi responsável, garantiu o retorno da disciplina, após longos anos formalmente fora do currículo escolar, provocando, assim, um impacto significativo no seu ensino, com a consolidação, já a partir de 2012, de ações que vão desde a inclusão da disciplina no Programa Nacional do Livro Didático (PNLD) e posterior publicação dos livros didáticos de filosofia, passando pela criação do Mestrado Profissional em Filosofia (Prof-Filo), bem como o fomento da formação e qualificação das licenciaturas em filosofia e da formação de seus professores pela Coordenação de Aperfeiçoamento de Pessoal de Nível Superior (CAPES), notadamente através dos Programa Institucional de Bolsas de Iniciação à Docência (PIBID) e Programa de Residência Pedagógica (PR).

Afinal, será mesmo que isto representará o fim da Filosofia no Ensino Médio? Haverá ainda possibilidades para ela? Se a resposta é sim, de que maneira? Quais 
são essas possibilidades? Estaria assegurada a própria formação do professor de Filosofia, numa licenciatura específica? Faria sentido esta formação específica, inclusive para a maioria das disciplinas, dado que foram incluídas como conteúdos em suas respectivas áreas? As questões, portanto, são muitas e inquietantes. O presente texto pretende ser consolidado a partir de possíveis respostas a essas questões, procurando ver possibilidades e caminhos para a disciplina de filosofia e as possibilidades de seu ensino neste contexto da reforma do ensino médio.

Apesar do esforço de consolidação da disciplina de filosofia, conforme a exposição feita acima, a mais recente reforma da educação brasileira provocou mais um revés curricular à referida disciplina, fazendo-a perder seu estatuto de obrigatoriedade e passando à categoria de estudos e práticas, como já visto, incluídas na Base Nacional Comum Curricular, conforme se lê no novo texto da LDB (9.394/96), em seu Art. 35, inciso IV, em seu § 20: "A Base Nacional Comum Curricular referente ao ensino médio incluirá obrigatoriamente estudos e práticas de educação física, arte, sociologia e filosofia."

Situação semelhante ocorreu ao ensino de Filosofia na década de 1960, notadamente com a primeira Lei de Diretrizes e Bases da Educação, Lei $n^{\circ} 4.024$ de 1961, que segundo Dutra e Del Pino (2010, p. 89), fora a responsável por tornar a disciplina de Filosofia não obrigatória no currículo escolar.

\footnotetext{
Com a instituição da primeira LDB em 1961 (Lei 4.024/61), a disciplina de Filosofia deixou de ser obrigatória e tornou-se complementar. Deste momento em diante, o ensino desta disciplina começou o seu processo de declínio quanto á sua valorização e inclusão nas grades curriculares das escolas. Ainda nesta mesma década, ocorreu no Brasil o chamado Golpe Militar, onde o exército assumiu o poder da nação e começou a ditar os rumos que o país deveria tomar. $\mathrm{O}$ trabalho de controle militar-nacional foi sistemático e atingiu todos os segmentos do país, inclusive a educação escolar. (DUTRA; DEL PINO, 2010, p. 89).
}

Posteriormente, na década de 1970, a disciplina de filosofia, não cabendo mais na proposta de um currículo de cunho eminentemente profissionalizante, conforme foi a proposta implantada pelo ministério da educação sob o regime militar, sendo a Lei 5.692, de 11 de agosto de 1971, fora definitivamente retirada e substituída por outras que expressavam a ideologia do sistema, tal como era a disciplina de Moral e Cívica. 


\begin{abstract}
Nas propostas curriculares do governo transparecia o seu caráter ideológico. Este caráter pode ser confirmado após a instituição do DecretoLei baixado pela Junta Militar em 1969, o qual tornou obrigatório o ensino de "Educação Moral e Cívica" em todas as modalidades de ensino. No final do grau médio a denominação da disciplina mudava para "Organização Social e Política (OSPB)", e no curso superior para "Estudos de Problemas Brasileiros." (DUTRA; DEL PINO, 2010, p.89-90).
\end{abstract}

Ao que parece, o discurso da qualificação para o trabalho, conforme novas exigências do mercado, serviu como um dos elementos justificadores do movimento que principiou a reforma e a retirada da filosofia enquanto disciplina, propriamente dita, do currículo escolar médio, que parece vir como efeito colateral em ambas as situações. No contexto da atual reforma, há diversos parágrafos incluídos na lei que podem corroborar o pretenso intuito desta referida tese. Exemplos disso podem ser encontrados no $\S 7^{\circ}$ do Art. 35 , que atesta que "os currículos do ensino médio deverão considerar a formação integral do aluno, de maneira a adotar um trabalho voltado para a construção de seu projeto de vida e para sua formação nos aspectos físicos e cognitivos e socioemocionais." (BRASIL, LDB, Lei 9.394/96). Também no Art. 36, há indicativo de que "o currículo do ensino médio será composto pela Base Nacional Comum Curricular (BNCC) e por itinerários formativos, que deverão ser organizados por meio da oferta de diferentes arranjos curriculares, conforme a relevância para o contexto local e a possibilidade dos sistemas (...)". Os chamados itinerários formativos, como roteiros de atividades e conteúdo, permitem o aprofundamento em dada área do conhecimento com uma melhor orientação do que o aluno pretenderá seguir profissionalmente, a partir da autonomia para escolher o seu possível "projeto de vida", qualquer que seja o caminho que ele optar, sendo o seu foco no ensino superior, ou na formação técnica profissionalizante ou ainda no empreendedorismo.

A Base Nacional Comum Curricular definirá direitos e objetivos de aprendizagem do ensino médio, conforme diretrizes do Conselho Nacional de Educação, nas seguintes áreas do conhecimento: 
I - linguagens e suas tecnologias

II - matemática e suas tecnologias

III - ciências da natureza e suas tecnologias

IV - ciências humanas e sociais aplicadas

$\S 1^{\circ} \mathrm{A}$ parte diversificada dos currículos de que trata o caput do art. 26, definida em cada sistema de ensino, deverá ser harmonizada à Base Nacional Comum Curricular e ser articulada a partir do contexto histórico, econômico, social, ambiental e cultural. (BRASIL, LDB, LEI N. 9.394/96).

Assim, conforme a nova base curricular, a organização, definição e oferta dos itinerários formativos ficarão a cargo dos sistemas de ensino e das redes escolares, considerando particularidades regionais e estruturais, bem como a demanda e o interesse dos alunos. Portanto, no que concerne à presença da filosofia no currículo, esta orientação pode representar um alento, conforme o que se depreende do excerto abaixo.

\begin{abstract}
A BNCC não exclui a filosofia nem dá diretrizes rígidas para a sua configuração no Ensino Médio. Ela mesma afirma explicitamente não constituir- se no currículo dessa fase formativa, mas apenas na definição das suas aprendizagens essenciais. $O$ fato de a filosofia ter deixado de ser disciplina obrigatória não significa que ela tenha saído do currículo nem que precise sair. O futuro da unidade curricular de filosofia ainda é incerto, pois a BNCC permite que ele seja decidido nas instâncias estaduais e municipais e mesmo nas escolas. (SAVIAN FILHO et. all, $\mathrm{S} / \mathrm{D})$.
\end{abstract}

Nesta nova conjuntura, além das aulas tradicionais ligadas à base comum, é possível que se abra um campo de possibilidades onde as unidades curriculares, incluindo-se aí a própria filosofia, ligadas aos itinerários formativos, possam ser apresentadas de maneira diferenciada, seja através de projetos, oficinas, seminários, ou outras atividades e práticas contextualizadas. Assim, a permanência da filosofia no currículo escolar médio, com protagonismo, exigirá esforços de diversos atores envolvidos no processo educativo. 
A permanência de filosofia como unidade curricular dependerá da resistência das escolas. Na elaboração de seus projetos pedagógicos, em função da reorganização que virá (definindo especializações na formação), as escolas podem manter o ensino de filosofia. Não apenas as escolas que se especializarão em "ciências humanas", mas mesmo as escolas especializadas em "ciências exatas" poderão ter horas de formação em filosofia. A melhor estratégia de resistência, neste momento, parece-nos estar na ação dos professores: começando por seus estudantes e pelo Conselho de Escola, eles podem iniciar um movimento de conscientização: (i) sobre a continuidade da filosofia como unidade curricular; e (ii) sobre a importância da filosofia na formação humana. A partir daí, em união com os professores da escola, do município, do estado e do país, os professores podem e devem lutar para que os projetos pedagógicos das escolas conservem filosofia (como também sociologia, história e geografia!). (SAVIAN FILHO et. all., S/D).

Desta forma, abrindo-se uma oportunidade de repensar as aulas, de uma maneira geral, as aulas de filosofia também poderiam ser repensadas a partir dessa perspectiva? Os autores referenciados acima indicam que sim, com possibilidades mesmo de uma renovação metodológica para a disciplina em questão.

\begin{abstract}
A BNCC, sem anular o modelo clássico da formação por aulas, oferece outros modelos formativos (laboratórios, oficinas etc.), válidos para todas as unidades curriculares. Nisso há uma possibilidade forte de encontrar itinerários formativos em filosofia, até mesmo com um aporte de modernidade metodológica. (SAVIAN FILHO et. all S/D).
\end{abstract}

A ideia, por exemplo, de apresentar a filosofia dentro de um conjunto de disciplinas eletivas, como aparenta ser o descortinar desse contexto, pode representar voos mais altos e mais distantes, inclusive para o professor de filosofia, dado que permitiria uma maior dinamicidade nas suas aulas, com abertura de um leque de novas metodologias e aproximações da filosofia com outras áreas do conhecimento, e outras unidades curriculares, alçando-a para além dos limites da própria área de Ciências Humanas. Conforme ressaltam Savian Filho et. all., (s/d), "parece-nos urgente inserir na resistência dos professores o esclarecimento de que a filosofia não faz parte das 'ciências humanas'." Pelo excerto, o autor procura esclarecer o sentido desta afirmação, retirando a Filosofia de qualquer encaixe ou amoldamento, o que é conforme ao seu verdadeiro caráter. 


\begin{abstract}
Por questões de facilidade, talvez não seja um problema incluí-la nessa rubrica, mas convém lembrar que ela a transcende; do contrário, não haveria filosofia da matemática, das ciências exatas, da biologia etc. Nesse ponto e indo além dele, a BNCC contém uma ambiguidade perniciosa: ela dilui a especificidade da filosofia e dá a entender que o trabalho de reflexão sobre a própria reflexão (bem como sobre pressupostos e métodos, e sobre os caminhos da abstração e da argumentação) pode ser feito por todas as unidades curriculares. Não deixa de haver certa parte de verdade nisso, pois é desejável que todas as áreas do saber explicitem seus pontos de partida e seus métodos, mas também é desejável que se reconheça que há uma área do saber na qual esse trabalho é realizado com toda a tecnicidade que ele requer e na qual se pode obter um maior grau de criticidade, como defende a própria BNCC. Não é necessário entrar aqui no debate sobre a identidade da filosofia; não dividamos as forças de resistência! O que importa é defender o ideal da atividade filosófica como o trabalho do phílos do saber, trabalho daquele que se interessa pelo saber por ele mesmo, e não em vista de sua mera aplicação ou do "saber fazer" tecnicista, autoritário e desumanizador. (SAVIAN FILHO et. all., S/D).
\end{abstract}

Nessa real possibilidade de trânsito pelas diversas áreas do conhecimento, a filosofia e seus professores podem ocupar o protagonismo naquilo que se espera deles, que consiste no estabelecimento de ininterrupto debate e constante reflexão, bem como no engajamento para o desenvolvimento técnico e criativo de sua prática pedagógica.

\begin{abstract}
A urgência de esclarecer os pontos já elencados confirma a necessidade de os professores de filosofia participarem do debate sobre o Ensino Médio (como também sobre o Ensino Fundamental), numa atitude de diálogo que procura encontrar caminhos para mostrar a importância da manutenção da unidade curricular de filosofia. A BNCC, do início ao fim, opera com conceitos que apenas a filosofia pode analisar até o limite reflexivo que tais conceitos exigem. Assim, com base na própria BNCC os professores dispõem de conteúdos em torno dos quais dialogar a fim de convencer sobre a importância da formação filosófica específica no Ensino Médio. Por exemplo, a BNCC opera com as ideias de dignidade humana, de sentido e atribuição de sentido, de teoria e experiência, de natureza e cultura, desconhecimento e contextos de produção de conhecimento, de universalidade e diferença etc. (SAVIAN FILHO et. all., S/D).
\end{abstract}

Com a definição e oferta dos itinerários formativos, com os alunos tendo a oportunidade de escolher aquilo que pretendem cursar, no sentido de enriquecer o projeto de sua opção, uma multiplicidade de temas da filosofia podem dar origem a diversas disciplinas eletivas em forma de cursos, por exemplo, dando margem para uma aproximação entre os diversos saberes e atendendo a demanda dos alunos. 


\section{Proposta de um Plano de curso de formação filosófica com os textos de C. S. Lewis}

Nesta compreensão de que as exigências vão no sentido de oferta da disciplina de filosofia no formato eletivo, nosso intuito, na presente proposta, consistiu na composição de um curso de formação filosófica no sentido de atender as prováveis demandas, conforme salientadas acima. Assim, a formação bem poderia atender a um pequeno grupo no sentido de formar monitores para as aulas de filosofia, bem como para a realização de eventos escolares tais como saraus e cafés filosóficos, como poderia atender a um público mais amplo, conforme o interesse demonstrado pelas temáticas escolhidas. De qualquer maneira, registre-se a possibilidade de adaptação a qualquer situação.

No escopo do trabalho, a intenção foi atrelar o ensino de filosofia com textos ficcionais, apreciando nestes aquilo que elegemos como a nossa categoria de análise, a imaginação e, ao mesmo tempo, considerando-a como o recurso metodológico apropriado para tecer esta aproximação, notadamente entre o texto literário lewisiano e a reflexão filosófica a partir de textos propriamente filosóficos de autores que se debruçaram sobre os aspectos filosóficos nas obras de Lewis, como é o caso do conjunto de textos compilados no livro As Crônicas de Nárnia e a Filosofia: O Leão, A Feiticeira e a Visão de Mundo, sob a coordenação de William Irwin.

Dentre os textos de Lewis, foram escolhidos alguns do conjunto das Crônicas de Nárnia, dentre eles O Sobrinho do Mago, A Viagem do Peregrino da Alvorada e a Última Batalha. Na composição das aulas, no total de cinco, ministradas entre o mês de abril e o mês de maio, cada texto de Lewis foi associado a um tema filosófico, cujo estudo foi norteado pelos textos dos autores do livro citado no parágrafo anterior, conforme detalhado abaixo no cronograma organizado: 
Cronograma e Organização do Material Didático

Aula 01 - O que é Imaginação? Imaginação e Filosofia

Webconferência de Abertura - C. S. Lewis e as histórias

Videoaula 01 - O que é imaginação?

Texto 01 - A Educação da Imaginação

Texto 02 - Nárnia e o Encanto da Filosofia (Jerry L. Walls)

Texto 03 - Um método para a descoberta da verdade (Umberto Eco).

Período: 19 a 24 de abril de 2021

Aula 02 - Ética e Conhecimento

Webconferência - Epistemologia da Virtude

Videoaula 02 - Epistemologia da Virtude

Texto 01 - O Sobrinho do Mago (C. S. Lewis)

Texto 02 - Epistemologia da Virtude: por que o Tio André não ouvia a fala dos animais (Kevin Kingorn)

Período: 26 a 30 de abril de 2021

Aula 03 - Estética

Webconferência - Sobre os Sentidos

Videoaula 03 - Os sentidos

Texto 01 - A Viagem do Peregrino da Alvorada

Texto 02 - A voz de Aslam: C. S. Lewis e a Magia do Som (Stephen H. Webb)

Período: 03 a 08 de maio de 2021

Aula 04 - Verdade e Certeza

Webconferência - Conhecer em Perspectiva

Videoaula 04 - O Conhecimento em Perspectiva

Texto 01 - A Última Batalha

Texto 02 - Não há fraude aqui: verdade e perspectiva (Bruce R. Reichenbach)

Período: 10 a 15 de maio de 2021 
Aula 05 - Desenvolvimento Moral

Webconferência - Desenvolvimento Moral

Videoaula 05 - Os Valores em Nárnia

Texto 01 - A Viagem do Peregrino da Alvorada

Texto 02 - Extreme Makeover - Reforma Total: desenvolvimento moral e o encontro com Aslam (Bill Davis)

Período: 17 a 22 de maio de 2021

Fonte: Os autores

O curso foi montado para ser ofertado de forma remota e seu conteúdo exibido através de videoaulas, e o material de estudo, tais como os textos nãofilosóficos e os propriamente filosóficos e vídeos, permeados pelos recursos de videoconferências e com acompanhamento por meio de grupo de WhatsApp. Assim, os recursos metodológicos que permitiram o andamento do curso foram: Internet; aplicativos diversos como Zoom, WhatsApp, Zoom Meet, bem como programas para exibição gráfica, como o Power Point; Textos em PDF; Celulares; Tablets; Notebooks

A participação no curso se deu através de convite durante aula virtual, bem como da exposição da proposta, que de imediato foi aceita e a adesão resultou na matrícula de 32 alunos. O número de inscritos foi bem além do que se esperava, dado que a formação tinha sido pensada para atender, no máximo, 20 alunos.

Como mencionado, as obras do escritor irlandês Clive Staples Lewis inspiraram essa proposta de curso, e assim, foram utilizados alguns, principalmente As Crônicas de Nárnia. Mas, aos que participaram do curso foi dada a orientação de que outros autores e seus textos podem ser utilizados em outras propostas, a depender da disposição dos alunos em procurar estudar e discutir os autores de suas preferências. 


\section{Considerações}

O primeiro registro que se deve deixar aqui, é sobre a boa adesão à proposta do curso de formação filosófica apresentado aos alunos, conforme as possibilidades abertas pelo novo currículo escolar, conforme a Base Nacional Comum Curricular. Mesmo que inicialmente o curso tenha sido formatado para atender, no máximo, 20 alunos, e dadas as dificuldades pelas quais passamos em decorrência da grave crise sanitária, 32 alunos solicitaram inscrição. Algumas respostas podem ser retiradas daqui para sanar as inquietantes perguntas feitas inicialmente neste texto. Ou seja, descortinam-se outras possibilidades para o ensino de filosofia, e a adesão voluntária dos alunos ao curso mostra boas perspectivas ao professor de filosofia.

É digno de nota que o referido curso foi ofertado a alunos do $3^{\circ}$ Ano do Ensino Médio da Escola de Ensino Médio Professora Adélia Brasil Feijó, localizada em Fortaleza, na avenida Contorno Sul, n. 1540, no Bairro Conjunto Esperança, bairro da periferia da cidade.

Mesmo com toda a dificuldade apresentada pelo momento a respeito do referido quadro sanitário, que forçou a remodelação das aulas, que por sua vez dependem de recursos vários e que nem sempre estão a funcionar a contento, registre-se o empenho dos alunos em dar cabo do compromisso assumido para participar das aulas. Claro que nem todos foram assíduos, ou tiveram participação em todas as aulas, mas demonstraram o desejo de prosseguir e não desistir da jornada. Ressaltamos aqui que muitos alunos apostaram nas aulas de filosofia com a finalidade de colher subsídios argumentativos para as elaborações de futuras redações. Isso também é significativo se pensarmos nas mudanças propostas que estão a exigir aproximações disciplinares e de áreas.

De forma geral, todos os alunos matriculados, com maior ou menor participação, concluíram as etapas traçadas na composição do curso e participaram da avaliação final, que consistiu em um questionário avaliativo do curso e de seu desenvolvimento.

O questionário aplicado, formatado como formulário do Google, constava de 10 (dez) questões em que os alunos optariam entre sim ou não e, em algum caso, 
um talvez, bem como a atribuição de uma pontuação. Ele fora disponibilizado para os alunos na própria sala de aula virtual da escola.

O intuito inicial era que os alunos fossem capacitados para a organização de alguns eventos de filosofia na escola, tais como simpósios, cafés filosóficos, saraus, seminários, dentre outras modalidades, dado que, nos anos anteriores, muitos alunos participantes do curso já haviam demonstrado interesse na organização e promoção de eventos dessa natureza. Com a migração para o ensino remoto, os ímpetos iniciais sofreram um certo arrefecimento, pois o ano de 2020 foi um período de adaptações. No entanto, vislumbra-se aí um vasto campo em que o professor de filosofia, com bastante imaginação, poderá trilhar ou abrir caminhos metodológicos para sua disciplina.

\section{Referências}

ARAÚJO, Matheus. Como Educar a Imaginação. Um guia para a leitura dos clássicos. [S.I.]: Instituto Dom Literário, sf. Disponível em: https://docero.com.br/doc/n8eev51. Acesso em 12 de abril de 2020.

BRASIL. Orientações curriculares para o ensino médio: ciências humanas e suas tecnologias. Brasília: Ministério da Educação; Secretaria da Educação Básica, 2006.

BRASIL. LDB, Lei 9.394/96. Disponível em: http://www.planalto.gov.br. Acesso em 27 de maio de 2021.

DUTRA, Jorge da Cunha. DEL PINO, Mauro Augusto Burkert. Resgate histórico do ensino de Filosofia nas escolas brasileiras: do século XVI ao séculi XXI. In.: InterMeio: revista do Programa de Pós-Graduação em Educação,Campo Grande, MS, v. 16, n. 31, p. 85-93, jan./jul. 2010.

IRWIN,William. As Crônicas de Nárnia e a Filosofia: O Leão, A Feiticeira e a Visão de Mundo. São Paulo: Masdras 2006.

LEWIS, C. S. A abolição do homem. Traduzido por Gabriele Greggersen, $1^{\text {a }}$ ed. Rio de Janeiro: Thomas Nelson Brasil, 2017.

LEWIS. As Crônicas de Nárnia. Vol. Ùnico. São Paulo: Martins Fontes, s/d. Disponível em: https://docero.com.br/doc/nns5c8x. Acesso em 15 de junho de 2018.

LEWIS. Como cultivar uma vida de leitura. 1. ed. Rio de Janeiro: Thomas Nelson Brasil, 2020. 
LINDBERG, Christian. O ensino de filosofia e a reforma educacional: o que fazer? Coluna ANPOF, 05 de Abril de 2019. Disponível em: http://anpof.org/portal. Acesso em 27 de maio de 2020.

MCGRATH, Alister. Conversando com C. S. Lewis. 1 ed. São Paulo: Planeta, 2014.

SAVIAN FILHO, Juvenal. et. All. A BNCC e o futuro da filosofia no Ensino Médio Hipóteses. ANPOF. Disponível em: http://www.anpof.org/portal/index.php/en/artigosem-destaque/1584-a-bncc-e-o-futuro-da-filosofia-no-ensino-medio-hipoteses. Acesso em: 29 de maio de 2021.

\section{(c) (1) (8)(2)}

This work is licensed under a Creative Commons Attribution-NonCommercial 4.0 International (CC BY-NC 4.0) 